\title{
Hypertension and Diabetes Mellitus are Features of Vascular Dementia, Not Alzheimer's Disease
}

\section{Javanshiri $K^{*}$, Haglund $M$ and Englund $E$}

Department of Clinical Sciences, Lund University, Sweden

\section{Background}

Alzheimer's Disease (AD) is the most prevalent type of dementia/ major cognitive disorder (40\%-70\% of cases) [1-4], still increasing in prevalence with the growing elderly population [5]. Over the past years, it has been proposed that Diabetes Mellitus (DM) [6,7] and Hypertension (HT) $[6,8]$ are risk factors for AD. These are well known risk factors for vascular dementia $(\mathrm{VaD})$ [9], which is a brain disorder where cerebrovascular pathologies are accountable for the cognitive impairment, without significant impact of other pathologies $[9,10]$. Thus, the pathogenesis of $\mathrm{VaD}$ is conceptually different from that of $\mathrm{AD}$. The purpose of this study was to investigate the prevalence of $\mathrm{DM}$ and $\mathrm{HT}$ in $\mathrm{AD}, \mathrm{VaD}$ and mixed $\mathrm{AD}-\mathrm{VaD}(\mathrm{MD})$.

\section{Material and Methods}

Autopsy reports from the clinical department of Pathology in Lund from 1992-2017 were analysed. All cases with 1) A clinical diagnosis of dementia/cognitive disorder; 2) A complete autopsy report and 3) a neuropathologically confirmed diagnosis of $\mathrm{AD}, \mathrm{VaD}$ or $\mathrm{MD}$ were included.

Clinical data regarding DM and HT were retrieved from the Swedish National Diabetes Register (NDR) and the medical records. The definition of HT was set, in accordance with contemporary guidelines, at a blood pressure of $\geq 140 / 90$ [11]. All subjects with anti-hypertensive treatment were defined as having HT. Regarding DM, only presence or absences of diagnosis were considered.

The procedures of the brain investigation were made according to standard procedures in our laboratory [12]. In brief it included a detailed examination of the entire brain and lobar regions on small and whole-brain coronal sections. $\mathrm{AD}$ was defined as Braak stage III or more $[13,14]$. VaD was defined as clear vascular ischemic pathology without significant neurodegenerative changes [15]. MD was defined as significant AD pathology (at least Braak stage III) and concomitant significant vascular-ischemic pathology [16-19]. The three groups were compared using crosstabs and Pearson Chi-Square test to test for significance, followed by pairwise comparisons and subsequent Bonferroni correction for multiple analyses. A p-value of 0.05 was considered statistically significant.

\section{Results}

A total of 268 subjects were included [18], the cohort of $\mathrm{AD}$ comprising 81 subjects (30\%), the MD group comprising 81 (30\%) and the $\mathrm{VaD}$ group holding 106 cases (40\%). Data regarding DM and HT was not obtainable in all subjects, but for DM the mean proportion of obtainable data was $65 \%(62 \%-70 \%)$ of the subjects and for HT the mean of obtainable data was $74 \%(70 \%-76 \%)$ of the subjects.

DM (calculated from obtainable data) was reported in $12 \%$ of the $\mathrm{AD}$ group compared to $31 \%$ of the $\mathrm{VaD}$ group $(\mathrm{p}<0.001)$, and to $19 \%$ of the MD group (Figure 1). Hypertension was reported in $37 \%$ of the $\mathrm{AD}$ group compared to $74 \%$ of the $\mathrm{VaD}$ group $(\mathrm{p}<0.001)$. $44 \%$ of the MD group reported with HT (Figure 2).

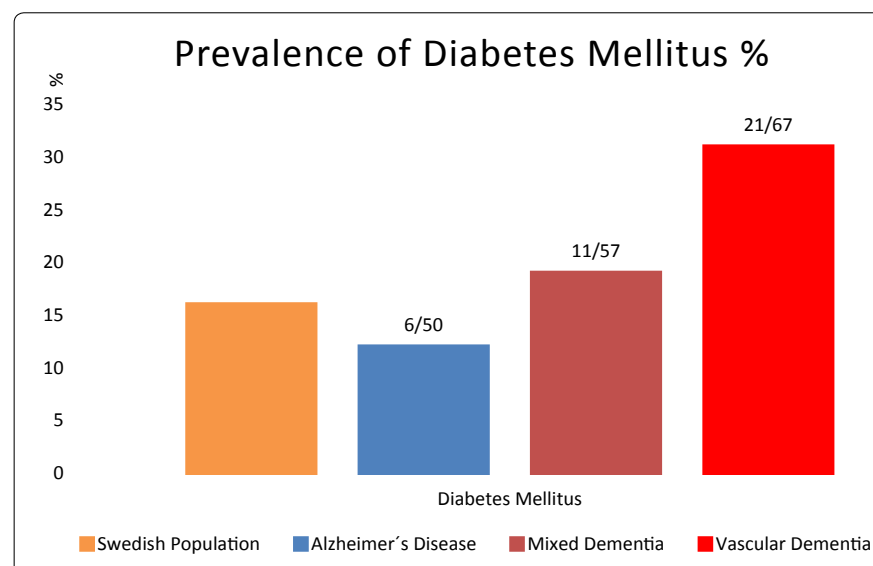

Figure 1: Prevalence of diabetes mellitus among the obtainable data in the different study groups (\%).

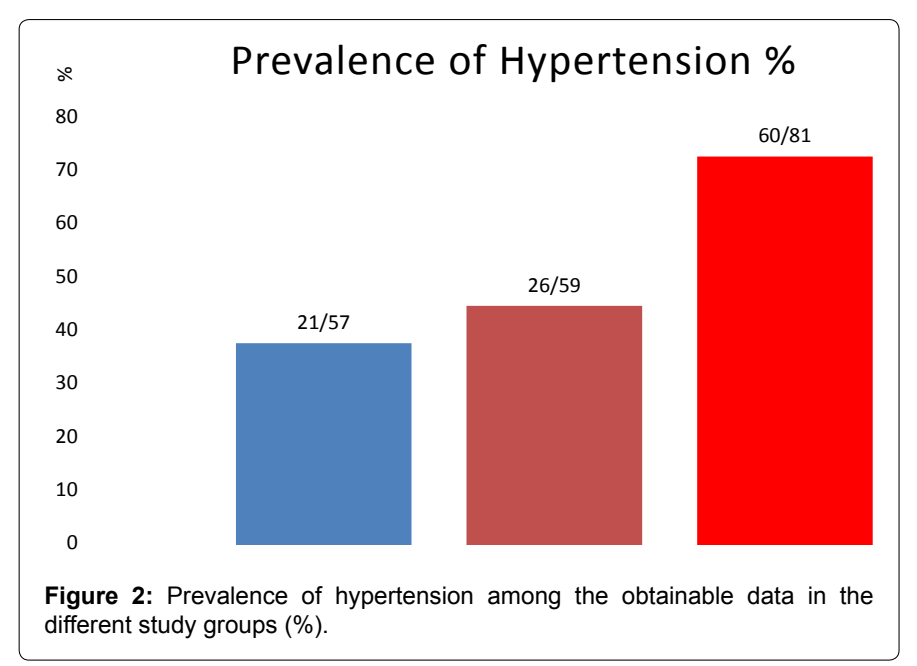

\section{Conclusion}

In this study we found that the prevalence of both DM and HT is clearly different between $\mathrm{AD}$ and $\mathrm{VaD}$, which is not surprising as they

*Corresponding author: Dr. K Javanshiri, Department of Clinical Sciences, Lund University, Sweden, Tel: +46737882498; E-mail: keivan.javanshiri@med.lu.se

Received January 03, 2019; Accepted January 13, 2019; Published January 19, 2019

Citation: Javanshiri K, Haglund M, Englund E (2019) Hypertension and Diabetes Mellitus are Features of Vascular Dementia, Not Alzheimer's Disease. J Neurol Neurophysiol 10: 482. doi:10.4172/2155-9562.1000482

Copyright: (c) 2019 Javanshiri K, et al. This is an open-access article distributed under the terms of the Creative Commons Attribution License, which permits unrestricted use, distribution, and reproduction in any medium, provided the original author and source are credited. 
Citation: Javanshiri K, Haglund M, Englund E (2019) Hypertension and Diabetes Mellitus are Features of Vascular Dementia, Not Alzheimer's Disease. J Neurol Neurophysiol 10: 482. doi:10.4172/2155-9562.1000482

display markedly dissimilar pathologies. In both studied risk factors, $\mathrm{MD}$ exhibited prevalence in between that of $\mathrm{AD}$ and $\mathrm{VaD}$.

Interestingly, and what could be interpreted as a strong indication that $\mathrm{DM}$ does not contribute to $\mathrm{AD}$ pathology, only $12 \%$ of our $\mathrm{AD}$ group had a diagnosis of $\mathrm{DM}$, a frequency lower than what is reported in the general Swedish population $(15,6 \%)$ in a similar age group, $>65$ years.

We believe that these findings stress the importance of telling $\mathrm{AD}$ and $\mathrm{VaD}$ apart, since it is fundamental to separate these two different entities for the assessment of risk factors, disease associations and possible treatment of two dissimilar diseases. This text is based on a published article in Journal of Alzheimer's Disease from Javanshiri et al.

\section{References}

1. Fratiglioni L, Launer LJ, Andersen K, Breteler MM, Copeland JR, et al. (2000) Incidence of dementia and major subtypes in Europe: A collaborative study of population-based cohorts. Neurology 54: 10-15.

2. Bruandet A, Richard F, Bombois S, Maurage CA, Deramecourt V, et al. (2009) Alzheimer disease with cerebrovascular disease and vascular dementia: Clinical features and course compared with Alzheimer disease. J Neurol Neurosurg Psychiatry 80: 133-139.

3. Grinberg LT, Nitrini R, Suemoto CK, Ferretti-Rebustini RE, Leite RE, et al. (2013) Prevalence of dementia subtypes in a developing country: A clinicopathological study. Clinics 68: 1140-1145.

4. Brunnstrom H, Gustafson L, Passant U, Englund E (2009) Prevalence of dementia subtypes: A 30-year retrospective survey of neuropathological reports. Arch Gerontol Geriatr 49: 146-149.

5. (2017) Organization WH, Dementia.

6. Qiu C (2012) Preventing alzheimer's disease by targeting vascular risk factors: Hope and gap. J Alzheimers Dis 32: 721-731.

7. Wijesinghe P, Shankar SK, Yasha TC, Gorrie C, Amaratunga D, et al. (2016) Vascular contributions in alzheimer's disease-related neuropathological changes: First autopsy evidence from a south asian aging population. J Alzheimers Dis 54: 1607-1618.
8. Newman AB, Fitzpatrick AL, Lopez O, Jackson S, Lyketsos C, et al. (2005) Dementia and alzheimer's disease incidence in relationship to cardiovascular disease in the cardiovascular health study cohort. J Am Geriatr Soc 53: 11011107.

9. Love SPA, Ironside J, Budka H (2015) Greenfield's neuropathology, crc press, New York.

10. Gorelick PB, Scuteri A, Black SE, Decarli C, Greenberg SM, et al. (2011) Vascular contributions to cognitive impairment and dementia: A statement for healthcare professionals from the American heart association/American stroke association. Stroke 42: 2672-2713.

11. Kjeldsen S, Feldman RD, Lisheng L, Mourad JJ, Chiang CE, et al. (2014) Updated national and international hypertension guidelines: A review of current recommendations. Drugs 74: 2033-2051.

12. Brunnstrom $\mathrm{H}$, Englund $\mathrm{E}$ (2009) Clinicopathological concordance in dementia diagnostics. Am J Geriatr Psychiatry 17: 664-670.

13. Braak H, Braak E (1991) Neuropathological stageing of alzheimer-related changes. Acta Neuropathol 82: 239-259.

14. Hyman BT, Phelps CH, Beach TG, Bigio EH, Cairns NJ, et al. (2012) National institute on aging-alzheimer's association guidelines for the neuropathologic assessment of alzheimer's disease. Alzheimers Dement 8: 1-13.

15. McAleese KE, Alafuzoff I, Charidimou A, de Reuck J, Grinberg LT, et al. (2016) Post-mortem assessment in vascular dementia: Advances and aspirations. BMC Med 14: 129.

16. Custodio N, Montesinos R, Lira D, Herrera-Perez E, Bardales Y, et al. (2017) Mixed dementia: A review of the evidence. Dement Neuropsychol 11: 364-370.

17. Moroney JT, Bagiella E, Desmond DW, Hachinski VC, Molsa PK, et al. (1997) Meta-analysis of the hachinski ischemic score in pathologically verified dementias. Neurology 49: 1096-1105.

18. Javanshiri K, Waldo ML, Friberg N, Sjovall F, Wickerstrom K, et al. (2018) Atherosclerosis, hypertension and diabetes in alzheimer's disease, vascular dementia, and mixed dementia: Prevalence and presentation. J Alzheimers Dis 65: $1247-1258$.

19. Andersson T, Ahlbom A, Carlsson S (2015) Diabetes prevalence in Sweden at present and projections for year 2050. PLoS ONE 10: 143084. 